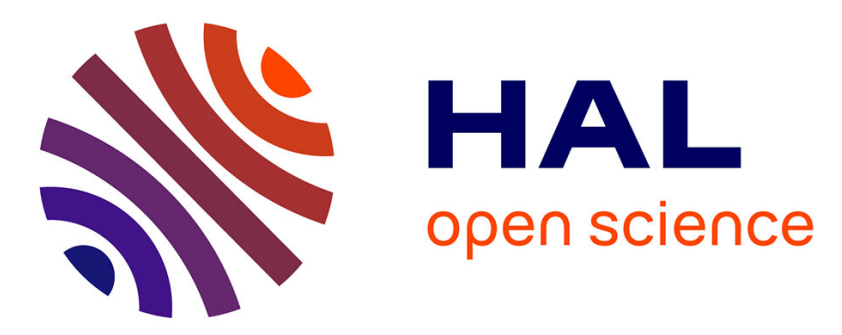

\title{
Advances in the Universal NMR Database: Toward the Determination of the Relative Configurations of Large Polypropionates
}

Etienne Fleury, Marie-Isabelle Lannou, Olivia Bistri, François Sautel, Georges Massiot, Ange Pancrazi, Janick Ardisson

\section{To cite this version:}

Etienne Fleury, Marie-Isabelle Lannou, Olivia Bistri, François Sautel, Georges Massiot, et al.. Advances in the Universal NMR Database: Toward the Determination of the Relative Configurations of Large Polypropionates. European Journal of Organic Chemistry, 2009, 2009 (29), pp.4992-5001. 10.1002/ejoc.200900616 . hal-02370630

\section{HAL Id: hal-02370630 \\ https://hal.science/hal-02370630}

Submitted on 20 Oct 2021

HAL is a multi-disciplinary open access archive for the deposit and dissemination of scientific research documents, whether they are published or not. The documents may come from teaching and research institutions in France or abroad, or from public or private research centers.
L'archive ouverte pluridisciplinaire HAL, est destinée au dépôt et à la diffusion de documents scientifiques de niveau recherche, publiés ou non, émanant des établissements d'enseignement et de recherche français ou étrangers, des laboratoires publics ou privés. 


\title{
Advances in the Universal NMR Database: Toward the Determination of the Relative Configurations of Large Polypropionates
}

\author{
Etienne Fleury ${ }^{[a]}$ Marie-Isabelle Lannou, ${ }^{\text {[a] }}$ Olivia Bistrii, ${ }^{\text {[a] }}$ François Sautel, ${ }^{[b]}$ \\ Georges Massiot, ${ }^{[b]}$ Ange Pancrazi, ${ }^{*[a]}$ and Janick Ardisson*[a]
}

Keywords: NMR spectroscopy / Polypropionates / Configuration determination / Computer chemistry / Databases / Statistical approach

\begin{abstract}
The relative stereochemical determination of naturally occurring large polyketides has proved to be critical, especially when the polyketides are available only in small quantities. Difficulties are often circumvented by the tedious synthesis either of adapted compound libraries (databases) or of all the presumed structures, because both methods allow efficient NMR comparison. To predict the stereochemistries of these frameworks, we have developed a straightforward method requiring neither the derivatisation of the natural product nor the synthesis of a new database of model stereoisomers. With the aid of ${ }^{13} \mathrm{C}$ NMR spectroscopy, the relative configurations
\end{abstract}

of the considered polypropionate segments are determined through a statistical UDB analysis of each included tetrad subunit followed by superposition of all predicted relative configurations of these tetrads. Examination of the different tetrads by statistical analysis consists of alternatively ruling out the $\Delta \delta$ values at positions where $\gamma$ and $\delta$ effects could interfere. In most cases this statistical ${ }^{13} \mathrm{C}$ NMR UDB approach leads to the stereochemical assignment of large polypropionate structures in a reliable way.

\section{Introduction}

Full structural elucidation of natural products and synthetic intermediates is a recurrent problem. In this field, NMR spectroscopic investigation of intact molecules remains the most powerful tool available for synthetic chemists to overcome the stereochemical question. In cases of cyclic compounds (with three- to six-membered rings), establishment of the relative configurations of substituents is often solved on the basis of vicinal proton coupling constants or nOe experiments. A much more challenging task is the determination of the configurations of polysubstituted open chains and macrocyclic compounds. One specific case in this regard involves complex natural products containing polyketide frameworks, often isolated in very low yields.

Faced with the problem of determining the configuration of a novel marine natural product featuring three contiguous propionate units, we envisaged the establishment of a straightforward method for the stereochemical assignment of large polypropionate structures through simple and conventional NMR spectroscopic data analysis.

[a] CNRS UMR 8638, Faculté de Pharmacie, Université Paris Descartes,

4 avenue de l'observatoire, 75270 Paris cedex 06, France

Fax: +33-1-43291403

E-mail: janick.ardisson@parisdescartes.fr

[b] CNRS/Pierre Fabre UMS 2597, Laboratoire Pierre Fabre,

3 rue des satellites, BP 94244, 31402 Toulouse cedex 4, France
In the specific case of two contiguous propionate units (tetrads), the Universal NMR Database (UDB) developed by Kishi has recently emerged as a very useful tool with which to tackle the problem of configuration analysis. ${ }^{[1]}$ The main asset of the method is that derivatisation into cyclic compounds is not necessary.

This approach is rooted in comparisons between the chemical shifts of compounds with unknown configurations and those of libraries of model compounds with known stereostructures. In this way, the method proceeds by determination of the minimum ${ }^{13} \mathrm{C}$ NMR $\Delta \delta$ value $\left(\Delta \delta=\delta_{\mathrm{X}}-\delta_{\mathbf{1 a}-\mathbf{h}}\right)$ between an unknown tetrad (X) and each of the eight possible model stereoisomers $\mathbf{1 a}-\mathbf{h}$ previously reported by Kishi (Scheme 1). To account for connectivity differences between the tetrad to be defined and the simplified models $\mathbf{1 a}-\mathbf{h}$ constituting the database, Kishi suggested the adjustment of all carbon chemical shifts of the unknown tetrad by a suitable factor, this to be derived from empirically predicted chemical shifts. The Schaller program delivered with the Chemdraw software package has been used for this purpose. Kishi's approach has been successfully applied to determine the relative configurations of unknown compounds with structures that incorporate unbranched tetrad units such as 1.

To date, the stereochemical determination of more complex branched polypropionates remains difficult, implying the time-consuming synthesis of all the presumed structures or the elaboration of adapted stereoisomer databases (sixteen stereoisomers for a pentad, thirty-two for a hexad). ${ }^{[2]}$ 

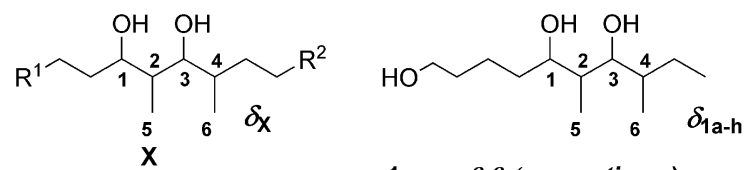

1a $\alpha \alpha \beta \beta$ (syn-anti-syn)

1b $\alpha \alpha \alpha \alpha$ (syn-syn-syn)

1c $\alpha \alpha \beta \alpha$ (syn-anti-anti)

1d $\alpha \alpha \alpha \beta$ (syn-syn-anti)

1e $\beta \alpha \beta \beta$ (anti-anti-syn)

1f $\beta \alpha \alpha \alpha$ (anti-syn-syn)

$\operatorname{1g} \beta \alpha \beta \alpha$ (anti-anti-anti)

1h $\beta \alpha \alpha \beta$ (anti-syn-anti)

\section{$\Delta \delta_{\min } \Leftrightarrow=>$ predicted configuration by Kishi's NMR UDB}

Scheme 1. Kishi's eight 1a-h diastereoisomers. "Positions 1-6" cited later relate to this model.

Here we present a powerful method for structural assignment of structures containing three contiguous propionate units (pentad and hexad patterns) based on an extension of Kishi's original UDB approach. Large polypropionates can be considered, from a structural viewpoint, as superpositions of different branched tetrad subunits. The proposed procedure utilizes a statistical approach applied to the different tetrads included in the studied segment. ${ }^{[3]}$

In the case of ${ }^{13} \mathrm{C}$ NMR spectroscopic examination of unit $\mathbf{A}$ (tetrad), containing two contiguous propionate components, addition of a methyl group $\alpha$ to a hydroxy group leads to some major changes in terms of chemical shifts (Scheme 2). In the initial C5-C8 fragment, the additional $\mathrm{Me}-\mathrm{C} 4$ induces a $\gamma$ effect at the $\mathrm{C} 6$ centre and $\delta$ effects at the $\mathrm{C} 7$ and $\mathrm{Me}-\mathrm{C} 6$ positions. Moreover, addition of this $\mathrm{Me}-\mathrm{C} 4$ results in the formation of the new $\mathrm{C} 7-\mathrm{C} 4$ tetrad $\mathbf{B}$, which is also perturbed by Me-C8 ( $\gamma$ and $\delta$ effects at the $\mathrm{C} 6$ and at the $\mathrm{C} 5$ and $\mathrm{Me}-\mathrm{C} 6$ positions, respectively). ${ }^{[4]}$
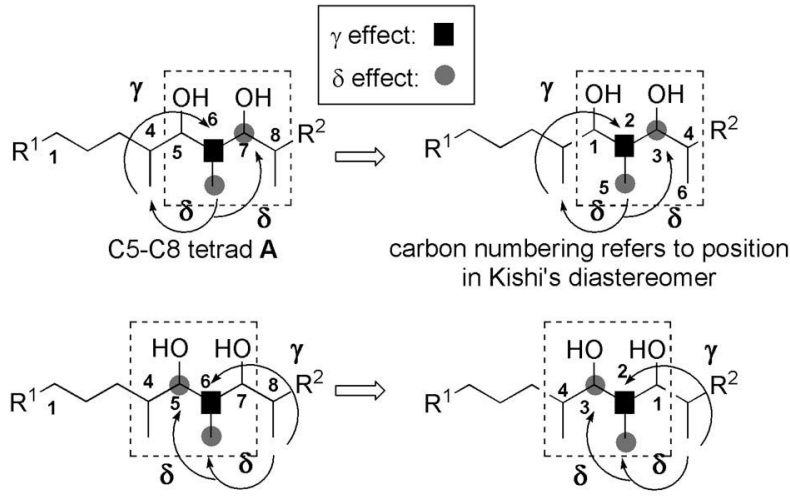

C7-C4 tetrad B

carbon numbering refers to position in Kishi's diastereomer

Scheme 2. $\alpha$-Methyl tetrad substitution and additional $\gamma$ and $\delta$ effects.

In ${ }^{13} \mathrm{C}$ NMR spectroscopy, $\gamma$ and $\delta$ effect values generated by a specific $\mathrm{X}$ moiety are closely related to the conformation of the molecule: as shown below, $\gamma$ effects range between 0.0 and $9.0 \mathrm{ppm}$ and $\delta$ effects between 0.0 and $3.0 \mathrm{ppm}$, depending on the relative stereochemistry (Scheme 3). ${ }^{[5]}$

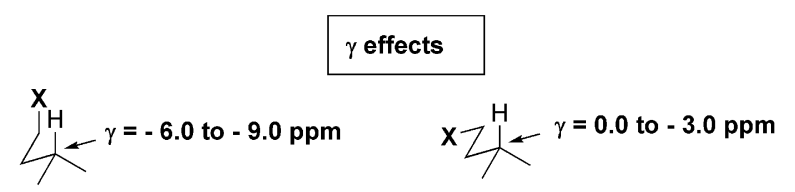

(1,3 diaxial)

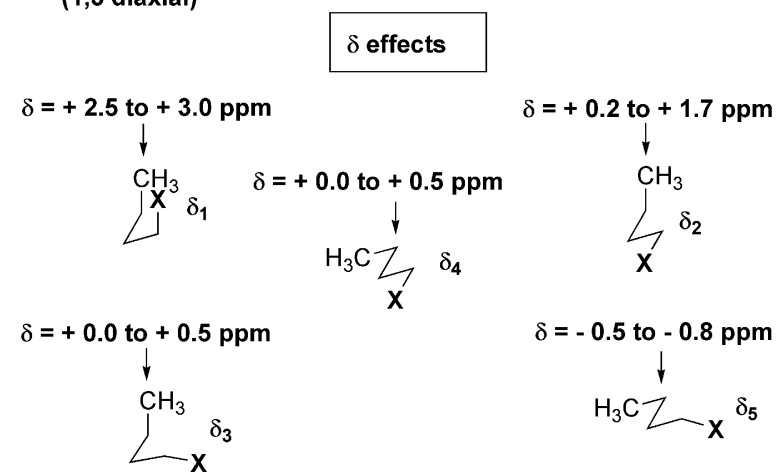

Scheme 3. The $\gamma$ and $\delta$ effects of a substituent $\mathrm{X}$ in ${ }^{13} \mathrm{C} \mathrm{NMR}$ spectroscopy.

To predict the relative stereochemistry of a $\mathrm{C} 4-\mathrm{C} 8$ pentad unit, Kishi's UDB method could be applied to tetrads A and $\mathbf{B}$ separately. As indicated before, the carbon chemical shifts of the tetrad of interest must first be adjusted with the aid of a ${ }^{13} \mathrm{C}$ NMR prediction program. ${ }^{[1]}$ In this case, tetrads $\mathbf{A}$ and $\mathbf{B}$ are branched. Although the predictive program takes the additional $\gamma$ and $\delta$ effects into account, average values of $2.5 \mathrm{ppm}$ for a $\gamma$ effect and of $0.3-0.6 \mathrm{ppm}$ for a $\delta$ effect are usually given, so the calculated adjustment $\mathbf{I}\left[\mathbf{I}=\delta_{\text {predicted }}\right.$ (A or B) tetrad $\left.-\delta_{\text {predicted Kishi's tetrad }}\right]$ is therefore not representative. As a consequence, in the UDB analysis of a tetrad such as $\mathbf{A}$ or $\mathbf{B}$, aberrant $\Delta \delta$ values can be observed at the positions that support these additional effects.

We hence propose a statistical approach in which the $\Delta \delta$ values are alternatively omitted at positions at which $\gamma$ and $\delta$ effects occur. Resulting misinterpretations are consequently avoided because the corresponding aberrant responses are removed from histograms and tables.

This approach was applied to different pentads encountered in compounds $\mathbf{2}$ and $\mathbf{3}$ described by Roush ${ }^{[6]}$ and in the synthetic aflastatin fragment 4 and saliniketal A (5), reported by Ikeda ${ }^{[7]}$ and Fenical ${ }^{[8]}$ respectively. The synthetic three-contiguous-propionate framework (hexad) present in aflastatin fragment $\mathbf{4}$ was also checked, as were those in sekothrixide (6) ${ }^{[9]}$ and zincophorin methyl ester (7) synthesized by Cossy ${ }^{[10]}$ (Scheme 4).

Each example was carefully chosen in order to explore a wide range of possibilities that can be encountered in the structural elucidation of polypropionate natural compounds.

In most cases, the proposed statistical ${ }^{13} \mathrm{C}$ NMR UDB approach leads to the stereochemical assignment of the large polypropionate structures without ambiguity. In certain specific examples, however, a single asymmetric centre may not be determined. Despite the incomplete conclusions, application of our statistical method dramatically decreases the number of diastereoisomers to synthesize for 

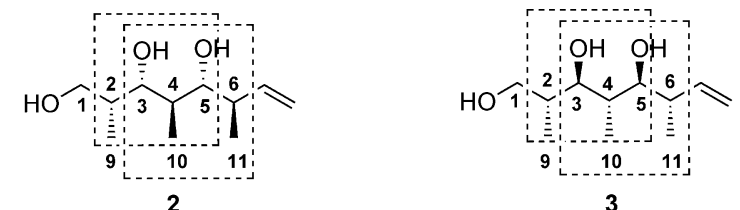

3

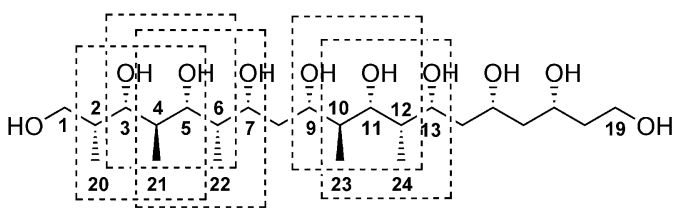

Synthetic aflastatin fragment 4
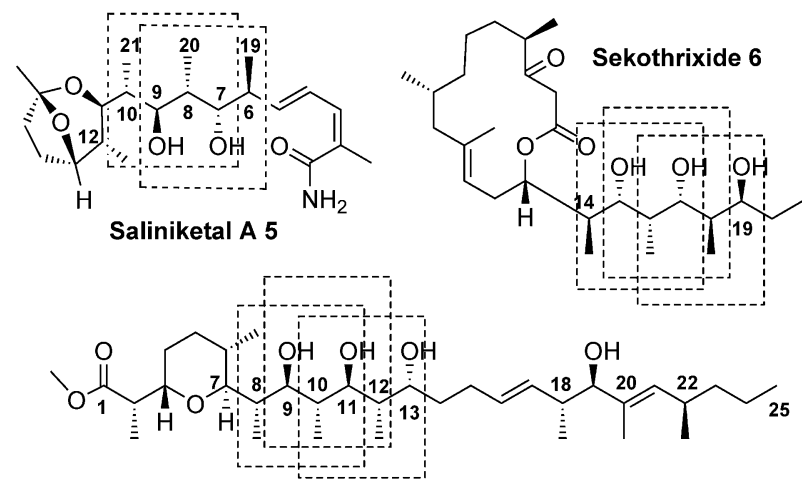

Zincophorin methylester 7

Scheme 4. Polypropionate segments examined by the statistical UDB approach.

NMR comparison and complete assignment. Moreover, consistently with Kishi's observations, ${ }^{[3]}$ we have noticed that classical ${ }^{1} \mathrm{H}$ NMR UDB analysis is a complementary tool. Indeed, a combination of ${ }^{13} \mathrm{C} \mathrm{NMR}$ and ${ }^{1} \mathrm{H} \mathrm{NMR}$ spectroscopy allows the determination of the entire relative stereochemistry of the polypropionates under consideration. Nevertheless, this complementarity investigation cannot be generalized and the systematic or unique use of ${ }^{1} \mathrm{H}$ NMR analysis has not so far been fully elucidated. Studies are currently under investigation.

\section{Results and Discussion}

The pentads and hexads 2-7 are regarded as superpositions of tetrad units. The relative configurations of the considered polypropionate segments are obtained by a statistical UDB analysis of each included tetrad subunit followed by superposition of all predicted relative configurations of these tetrads. For reasons of convention, the hydroxy function is considered to be the starting point of a tetrad. ${ }^{[4]}$ In this study, different examples evidence $\alpha$ (and/or $\beta$ ) substitution with methyl, hydroxy or cyclic ether groups (Scheme 4).

Analysis of compound $\mathbf{2}$ is described fully, whereas for reasons of simplification only the results of the statistical analysis are displayed for other compounds (see Supporting Information for full data description).

\section{Structural Assignment of Pentad Structures}

\section{NMR Analysis of the Pentad Unit of 2}

Pentad 2 (see Schemes 4 and 5) was regarded as an $\alpha$ methyl-substituted tetrad. The UDB method could consequently be applied to each dipropionate unit (C3-C6 and C5-C2). ${ }^{[4]}$
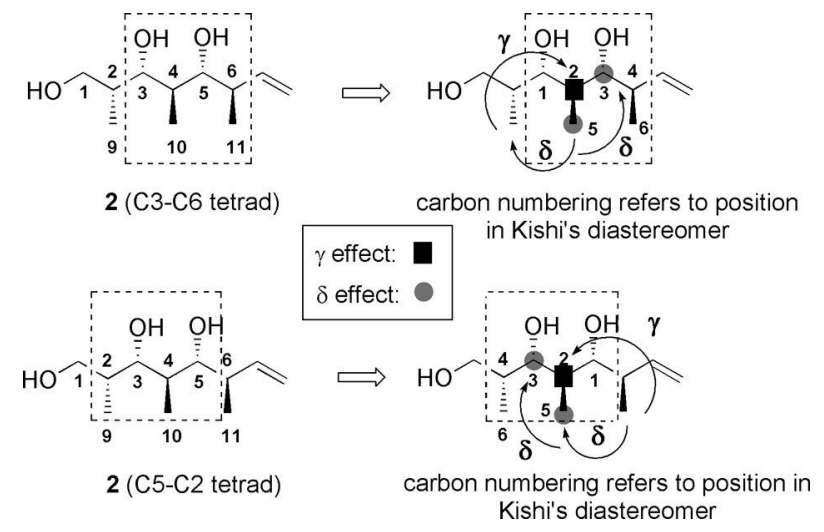

Scheme 5. Compound 2 (C3-C6 and C5-C2 tetrads) examined by the statistical UDB approach.

As mentioned above, the first step consists of adjustment of the reported ${ }^{13} \mathrm{C}$ NMR values (Table 1) by removal of a calculated increment $\mathbf{I}\left(\mathbf{I}=\delta_{\text {predicted } \mathrm{A}}-\delta_{\text {predicted } \mathrm{K}}\right)$. This enables the direct comparison $\left(\Delta \delta=\delta_{\mathrm{x}}-\delta_{\mathbf{1 a}-\mathbf{h}}\right)$ of ${ }^{13} \mathrm{C} \mathrm{NMR}$ spectroscopic data for Kishi's diastereoisomers ${ }^{[1 \mathrm{~b}]}$ and for the tetrad under consideration. Variations in $\Delta \delta$ are highlighted in Table 2 and Figure 1. The predicted relative configuration of the studied tetrad corresponds to the configuration of Kishi's diastereoisomer associated with the minimum $\Sigma|\Delta \delta|$ value.

Table 1. Predicted and adjusted ${ }^{13} \mathrm{C}$ NMR $\delta$ values for compound 2 (C3-C6 tetrad A).

\begin{tabular}{|c|c|c|c|c|c|c|}
\hline $\begin{array}{l}\text { No. }{ }^{[\mathrm{a}]} \\
\mathrm{C} \\
2\end{array}$ & $\begin{array}{c}\delta^{13} \mathrm{C} \\
\text { predicted }^{[\mathrm{b}]} \\
\mathbf{2} \\
\delta_{\mathrm{A}}\end{array}$ & $\begin{array}{l}\text { Position } \\
\text { in } \\
\text { Kishi's } \\
\text { models }^{[\mathrm{c}]}\end{array}$ & $\begin{array}{c}\delta{ }^{13} \mathrm{C} \\
\text { predicted } \\
\text { Kishi's } \\
\text { model } \\
\delta_{\mathrm{K}}\end{array}$ & $\delta_{\mathrm{A}}-\delta_{\mathrm{K}}$ & $\begin{array}{c}\delta^{13} \mathrm{C} \\
\text { reported } \\
\left(\mathrm{CDCl}_{3}\right) \\
\mathbf{2} \\
\delta\end{array}$ & $\begin{array}{c}\delta{ }^{13} \mathrm{C} \\
\text { adjusted } \\
\mathbf{2}\end{array}$ \\
\hline 3 & 77.3 & 1 & 69.7 & 7.6 & 81.2 & 73.6 \\
\hline 4 & 41.0 & 2 & 43.4 & -2.4 & 38.7 & 41.1 \\
\hline 5 & 76.2 & 3 & 80.6 & -4.4 & 79.9 & 84.3 \\
\hline 6 & 43.9 & 4 & 38.9 & 5.0 & 40.4 & 35.4 \\
\hline 10 & 9.3 & 5 & 8.9 & 0.4 & 12.9 & 12.5 \\
\hline 11 & 15.6 & 6 & 14.8 & 0.8 & 17.5 & 16.7 \\
\hline
\end{tabular}

[a] Carbon numbering corresponds to compound 2. [b] CambridgeSoft ChemNMR installed in CS Chem-Draw Package was used for NMR data predictions. [c] Positions refer to Kishi's diastereoisomers.

Our statistical approach, in which positions 2, 3 and 5 were alternatively or simultaneously not taken into account in the determination of $\Sigma|\Delta \delta|$, also led to this result (Table 2, $2^{\text {nd }}$ part). In general, $\Sigma|\Delta \delta|$ values in which $\gamma$ effect positions are subtracted (in this example, position 2), are considered a priority. 
Table 2. Differences in carbon chemical shifts (ppm) between $\mathbf{2}$ and $\mathbf{1 a}-\mathbf{h}(\mathrm{C} 3-\mathrm{C} 6)$ - statistical study of the C3-C6 tetrad of $\mathbf{2}$.

\begin{tabular}{|c|c|c|c|c|c|c|c|c|}
\hline$\Delta \delta$ & $\Delta \delta$ & $\Delta \delta$ & $\Delta \delta$ & $\Delta \delta$ & $\Delta \delta$ & $\Delta \delta$ & $\Delta \delta$ & \\
\hline 1a & $1 b$ & $1 c$ & 1d & $1 \mathrm{e}$ & 1f & $1 \mathrm{~g}$ & $1 \mathrm{~h}$ & No. ${ }^{[a]}$ \\
\hline$s-a-s$ & $s-s-s$ & $s-a-a$ & $s-s-a$ & $a-a-s$ & $a-s-s$ & $a-a-a$ & $a-s-a$ & \\
\hline 0.05 & -3.40 & 1.32 & -3.82 & -3.08 & -2.88 & -2.94 & -3.00 & 1 \\
\hline 2.07 & 3.22 & 3.29 & 3.30 & 0.22 & 2.88 & 0.31 & 2.96 & 2 \\
\hline 6.67 & 2.77 & 3.94 & 2.89 & 5.00 & 9.02 & 2.27 & 9.43 & 3 \\
\hline-1.61 & -2.23 & -2.08 & -2.32 & -1.42 & -1.95 & -1.61 & -2.20 & 4 \\
\hline 0.63 & 7.81 & 0.87 & 8.33 & -0.47 & 1.68 & -0.86 & 2.02 & 5 \\
\hline 3.91 & 1.58 & 0.92 & 1.83 & 5.14 & 1.38 & 0.02 & 1.87 & 6 \\
\hline 14.94 & 21.01 & 12.42 & 22.49 & 14.89 & 19.79 & 8.01 & 21.48 & $\Sigma|\Delta \delta|$ \\
\hline 12.87 & 17.79 & 9.13 & 19.19 & 14.67 & 16.91 & 7.70 & 18.52 & -2 \\
\hline 8.27 & 18.24 & 8.48 & 19.60 & 9.89 & 10.77 & 5.74 & 12.05 & -3 \\
\hline 6.20 & 12.25 & 5.19 & 16.30 & 9.67 & 7.89 & 5.43 & 9.09 & $-2-3$ \\
\hline 7.64 & 10.43 & 7.61 & 11.27 & 9.42 & 9.09 & 4.88 & 10.03 & $-3-5$ \\
\hline
\end{tabular}

[a] Numbers refer to positions in Kishi's diastereoisomers $\mathbf{1 a}-\mathbf{h}$.

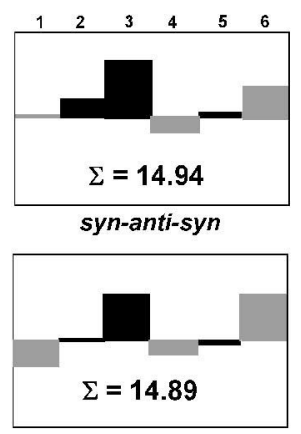

anti-anti-syn
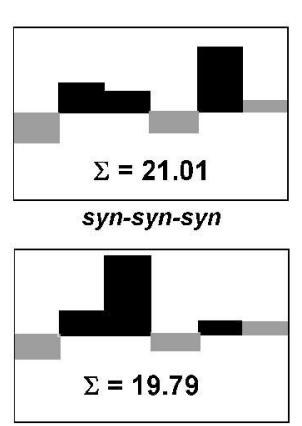

anti-syn-syn
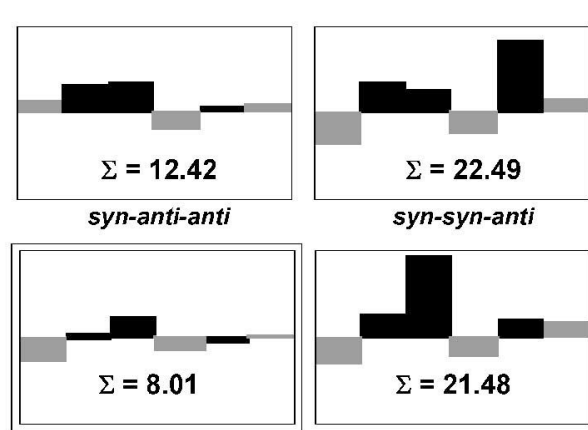

anti-anti-anti

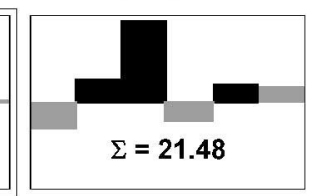

anti-syn-anti

Figure 1. Histograms for the C3-C6 tetrad of $2\left({ }^{13} \mathrm{C}\right.$ NMR analysis). In each figure, the framed histogram corresponds to the correct relative configuration through Kishi's UDB method. Positions highlighted in grey are not affected by additional $\gamma$ or $\delta$ effects.

In other words, examination at positions 1,4 and 6 (see histograms in Figure 1), which are not affected by additive $\gamma$ or $\delta$ effects, was sufficient clearly to indicate the correct relative configuration.

For the second C5-C2 tetrad, both syn-anti-syn and antianti-syn relative configurations emerged as satisfactory candidates by statistical analysis (Table 3 and Figure 2).

Table 3. Statistical study of the C5-C2 tetrad of $2\left({ }^{13} \mathrm{C}\right.$ NMR analysis).

\begin{tabular}{|c|c|c|c|c|c|c|c|c|}
\hline $\begin{array}{c}\Delta \delta \\
\mathbf{1 a} \\
s-a-s\end{array}$ & $\begin{array}{c}\Delta \delta \\
\mathbf{1 b} \\
S-S-S\end{array}$ & $\begin{array}{c}\Delta \delta \\
\mathbf{1 c} \\
s-a-a\end{array}$ & $\begin{array}{c}\Delta \delta \\
\mathbf{1 d} \\
s-s-a\end{array}$ & $\begin{array}{c}\Delta \delta \\
\mathbf{1 e} \\
\boldsymbol{a}-\boldsymbol{a}-\boldsymbol{s}\end{array}$ & $\begin{array}{c}\Delta \delta \\
\mathbf{1 f} \\
a-s-S\end{array}$ & $\begin{array}{c}\Delta \delta \\
\mathbf{1 g} \\
a-a-a\end{array}$ & $\begin{array}{c}\Delta \delta \\
\mathbf{1 h} \\
a-s-a\end{array}$ & No. \\
\hline-0.15 & -3.60 & 1.12 & -4.02 & -3.28 & -3.08 & -3.14 & -3.20 & 1 \\
\hline 2.07 & 3.22 & 3.29 & 3.30 & 0.22 & 2.88 & 0.31 & 2.96 & 2 \\
\hline 6.87 & 2.97 & 4.14 & 3.09 & 5.20 & 9.22 & 2.47 & 9.63 & 3 \\
\hline-1.31 & -1.93 & -1.78 & -2.02 & -1.12 & -1.65 & -1.31 & -1.90 & 4 \\
\hline 0.63 & 7.81 & 0.87 & 8.33 & -0.47 & 1.68 & -0.86 & 2.02 & 5 \\
\hline-0.39 & -2.72 & -3.38 & -2.47 & 0.84 & -2.92 & -4.28 & -2.43 & 6 \\
\hline 11.42 & 22.25 & 14.58 & 23.23 & 11.13 & 21.43 & 12.37 & 22.14 & $\Sigma|\Delta \delta|$ \\
\hline 9.35 & 19.03 & 11.29 & 19.93 & 10.91 & 18.55 & 12.06 & 19.18 & -2 \\
\hline 4.55 & 19.28 & 10.44 & 20.14 & 5.93 & 12.21 & 9.90 & 12.51 & -3 \\
\hline 2.48 & 16.06 & 7.15 & 16.84 & 5.71 & 9.33 & 9.59 & 9.55 & $-2-3$ \\
\hline 3.92 & 11.47 & 9.57 & 11.81 & 5.46 & 10.53 & 9.04 & 10.49 & $-3-5$ \\
\hline
\end{tabular}

However, the predicted anti-anti-anti structure for C3-C6 constrained the $\mathrm{C} 5-\mathrm{C} 2$ unit to possess an anti-anti- $x$ relative stereochemistry, and therefore anti-anti-syn. Note that the $\Delta \delta$ values at positions 2, 3 and 5 shown in Figure 2 also reflect the additional $\gamma$ and $\delta$ effects generated by the $\alpha$ methyl group with regard to the C5-C2 fragment (see also Scheme 5).

Consequently, extension of the UDB method to the pentad structure of $\mathbf{2}$ gave the correct syn-anti-anti-anti relative stereochemistry prediction.

\section{NMR Analysis of the Pentad Unit of 3}

In a second application of the statistical approach, compound 3 was subjected to complete ${ }^{13} \mathrm{C}$ NMR spectroscopic data analysis (Scheme 4 and Scheme 6).

In the following examples, only $\Sigma|\Delta \delta|$ values are reported, because they represent the crucial values for accurate attribution of the relative stereochemistry (see Supporting Information for full data). As shown below, examination of the C3-C6 segment showed the emergence of two preferential configurations: anti-syn-syn and anti-anti-anti (Table 4).

In contrast, analysis of the $\mathrm{C} 5-\mathrm{C} 2$ unit led to the unambiguous prediction of an anti-anti-anti configuration (Table 5).

Again, the anti-anti-anti prediction for the $\mathrm{C} 5-\mathrm{C} 2$ tetrad implied an anti-anti-x relative stereochemistry for the first C3-C6 tetrad. As a result, an anti-anti-anti configuration could be predicted for the $\mathrm{C} 3-\mathrm{C} 6$ fragment. 

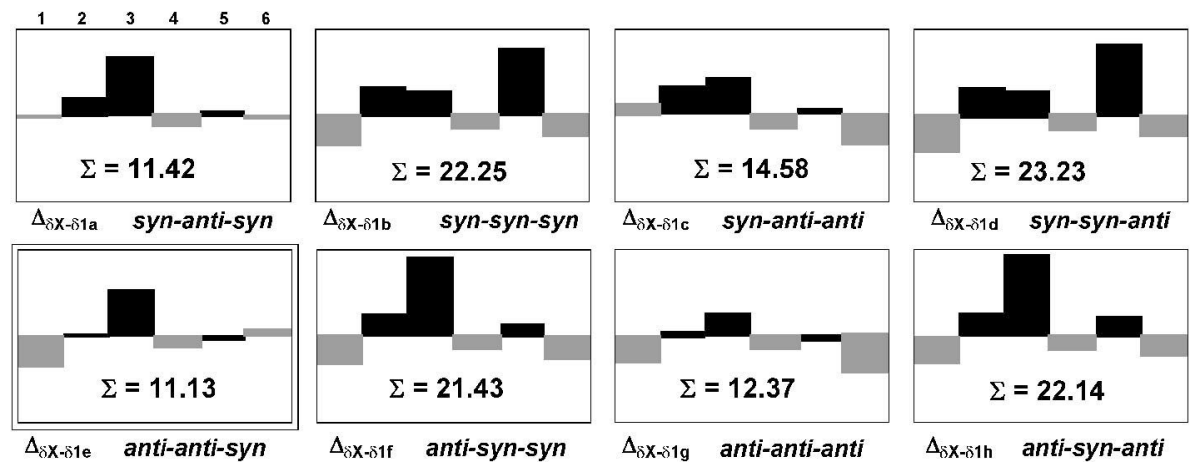

Figure 2. Histograms for the C5-C2 tetrad of $2\left({ }^{13} \mathrm{C}\right.$ NMR analysis).

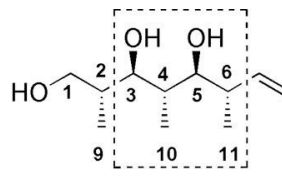

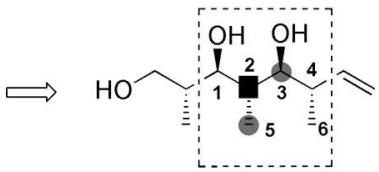

3 (C3-C6 tetrad)
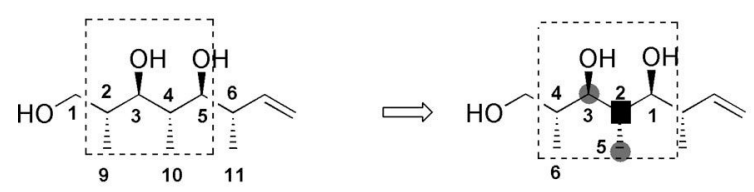

3 (C5-C2 tetrad)

Scheme 6. Compound 3 (C3-C6 and $\mathrm{C} 5-\mathrm{C} 2$ tetrads) examined by the statistical UDB approach.

Table 4. Statistical study of the C3-C6 tetrad of $3\left({ }^{13} \mathrm{C}\right.$ NMR analysis).

\begin{tabular}{|c|c|c|c|c|c|c|c|c|}
\hline$\Delta \delta$ & $\Delta \delta$ & $\Delta \delta$ & $\Delta \delta$ & $\Delta \delta$ & $\Delta \delta$ & $\Delta \delta$ & $\Delta \delta$ & \\
\hline $1 \mathrm{a}$ & $1 \mathrm{~b}$ & $1 c$ & $1 d$ & $1 \mathrm{e}$ & 1f & $1 \mathrm{~g}$ & 1h & No. \\
\hline$s-a-s$ & $S-S-S$ & $s-a-a$ & $s-s-a$ & $a-a-s$ & $a-s-s$ & $a-a-a$ & $a-s-a$ & \\
\hline 20.84 & 27.01 & 17.82 & 28.49 & 18.95 & 19.03 & 12.29 & 27.48 & $\Sigma|\Delta \delta|$ \\
\hline 18.27 & 23.29 & 14.03 & 24.69 & 18.23 & 15.65 & 11.48 & 24.02 & -2 \\
\hline 11.17 & 21.24 & 10.88 & 22.60 & 10.95 & 7.01 & 7.02 & 15.05 & -3 \\
\hline 8.60 & 11.75 & 7.09 & 18.80 & 10.23 & 3.63 & 6.21 & 11.59 & $-2-3$ \\
\hline 8.14 & 11.03 & 7.61 & 11.87 & 9.02 & 2.93 & 5.48 & 10.63 & $-3-5$ \\
\hline
\end{tabular}

Table 5. Statistical study of the C5-C2 tetrad of $3\left({ }^{13} \mathrm{C}\right.$ NMR analysis).

\begin{tabular}{|c|c|c|c|c|c|c|c|c|}
\hline$\Delta \delta$ & $\Delta \delta$ & $\Delta \delta$ & $\Delta \delta$ & $\Delta \delta$ & $\Delta \delta$ & $\Delta \delta$ & $\Delta \delta$ & \\
\hline $1 \mathrm{a}$ & $1 b$ & $1 c$ & 1d & $1 \mathrm{e}$ & 1f & $1 \mathrm{~g}$ & $1 \mathrm{~h}$ & No. \\
\hline$s-a-s$ & $S-S-S$ & $s-a-a$ & $s-s-a$ & $a-a-s$ & $a-s-s$ & $a-a-a$ & $a-s-a$ & \\
\hline 21.44 & 21.91 & 18.92 & 23.39 & 15.29 & 20.69 & 7.19 & 22.38 & $\Sigma|\Delta \delta|$ \\
\hline 18.87 & 18.19 & 15.13 & 19.59 & 14.57 & 17.31 & 6.38 & 18.92 & -2 \\
\hline 14.87 & 19.24 & 15.08 & 20.60 & 10.39 & 11.77 & 5.02 & 13.05 & -3 \\
\hline 12.30 & 12.85 & 11.29 & 16.80 & 9.67 & 8.39 & 4.21 & 9.59 & $-2-3$ \\
\hline 11.84 & 9.03 & 11.81 & 9.87 & 8.46 & 7.69 & 3.48 & 8.63 & $-3-5$ \\
\hline
\end{tabular}

In conclusion, the complete anti-anti-anti-anti stereochemistry of $\mathbf{3}$ was fully deduced through statistical analysis.

\section{NMR Analysis of the C9-C13 Pentad of the Synthetic Aflastatin Fragment 4}

Another interesting situation is that of the synthetic C9$\mathrm{C} 13$ aflastatin fragment $\mathbf{4}$. This could be regarded as an $\alpha-$ hydroxy-substituted tetrad and introduction of this hydroxy function creates a new tetrad (Schemes 4 and 7). Application of the extended UDB method was therefore relevant for this new structure.

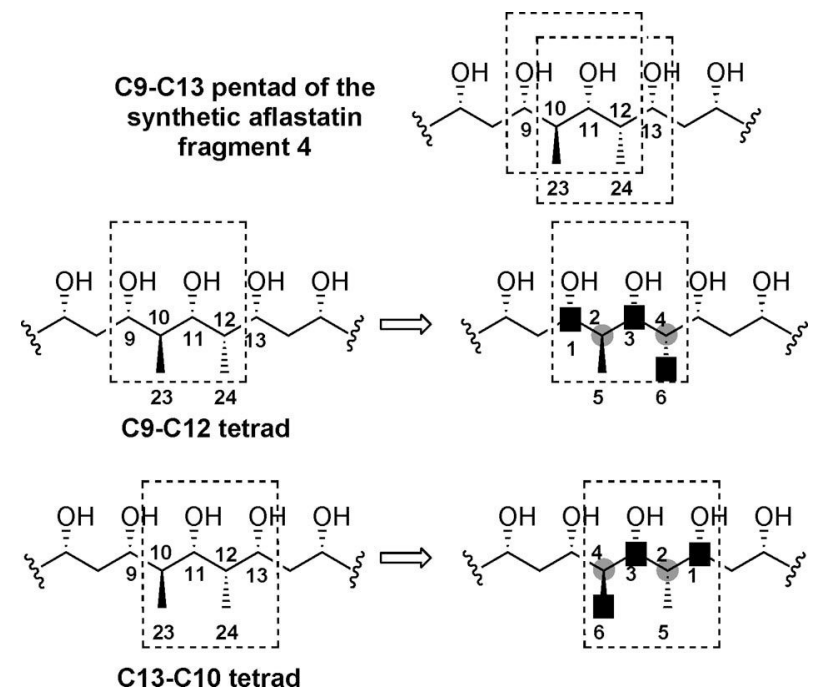

Scheme 7. C9-C13 pentad of the synthetic aflastatin fragment 4 (C9-C12 and C13-C10 tetrads) examined by the statistical UDB approach.

In this case, as in those of compounds $\mathbf{2}$ and $\mathbf{3}$, combination of the predictions for the C9-C12 and C13-C10 tetrads (anti-anti-syn and syn-syn-anti, respectively; see Tables 6, 7 and Supporting Information), allowed prediction of the correct anti-anti-syn-syn configuration for the C9-C13 segment of the synthetic aflastatin intermediate 4 . This result validated the statistical method for $\alpha$-hydroxy-substituted tetrads.

Table 6. Statistical study of the C9-C12 tetrad of $4\left({ }^{13} \mathrm{C}\right.$ NMR analysis).

\begin{tabular}{|c|c|c|c|c|c|c|c|c|}
\hline$\Delta \delta$ & $\Delta \delta$ & $\Delta \delta$ & $\Delta \delta$ & $\Delta \delta$ & $\Delta \delta$ & $\Delta \delta$ & $\Delta \delta$ & \\
\hline 1a & $1 b$ & $1 c$ & 1d & $1 e$ & 1f & $1 \mathrm{~g}$ & $1 \mathrm{~h}$ & No. \\
\hline$s-a-s$ & $S-S-S$ & $s-a-a$ & $s-s-a$ & $a-a-s$ & $a-s-s$ & $a-a-a$ & $a-s-a$ & \\
\hline 20.83 & 21.24 & 22.60 & 21.79 & 15.15 & 22.27 & 17.88 & 23.25 & $\Sigma|\Delta \delta|$ \\
\hline 5.81 & 11.30 & 11.23 & 14.57 & 3.68 & 9.19 & 9.38 & 10.35 & $-1-3$ \\
\hline 5.25 & 9.26 & 6.77 & 11.15 & 3.64 & 5.91 & 4.33 & 7.07 & $-1-3-6$ \\
\hline 1.42 & 6.09 & 4.83 & 8.25 & 0.38 & 4.18 & 5.86 & 4.59 & $-1-3-2-4$ \\
\hline
\end{tabular}


Table 7. Statistical study of the C13-C10 tetrad of $4\left({ }^{13} \mathrm{C}\right.$ NMR analysis).

\begin{tabular}{|c|c|c|c|c|c|c|c|c|}
\hline$\Delta \delta$ & $\Delta \delta$ & $\Delta \delta$ & $\Delta \delta$ & $\Delta \delta$ & $\Delta \delta$ & $\Delta \delta$ & $\Delta \delta$ & \\
\hline $1 \mathrm{a}$ & $1 \mathrm{~b}$ & 1c & 1d & 1e & 1f & $1 \mathrm{~g}$ & 1h & No. \\
\hline$s-a-s$ & $S-S-S$ & $s-a-a$ & $s-s-a$ & $a-a-s$ & $a-s-s$ & $a-a-a$ & $a-s-a$ & \\
\hline 28.07 & 17.78 & 20.16 & 12.95 & 27.87 & 23.79 & 20.58 & 22.93 & $\Sigma|\Delta \delta|$ \\
\hline 10.65 & 5.44 & 6.39 & 3.33 & 14.00 & 8.31 & 9.68 & 7.63 & $-1-3$ \\
\hline 6.01 & 2.70 & 5.65 & 1.55 & 8.84 & 6.39 & 9.53 & 5.71 & $-1-3-6$ \\
\hline 8.98 & 4.31 & 5.57 & 2.15 & 10.70 & 6.22 & 6.16 & 5.81 & $-1-3-2-4$ \\
\hline
\end{tabular}

\section{NMR Analysis of the C6-C10 Pentad of Saliniketal A (5)}

The ${ }^{13} \mathrm{C}$ NMR spectroscopic data for the two C9-C6 and C7-C10 segments of saliniketal A (5) were then examined and subjected to statistical analysis (Scheme 4 and Scheme 8).
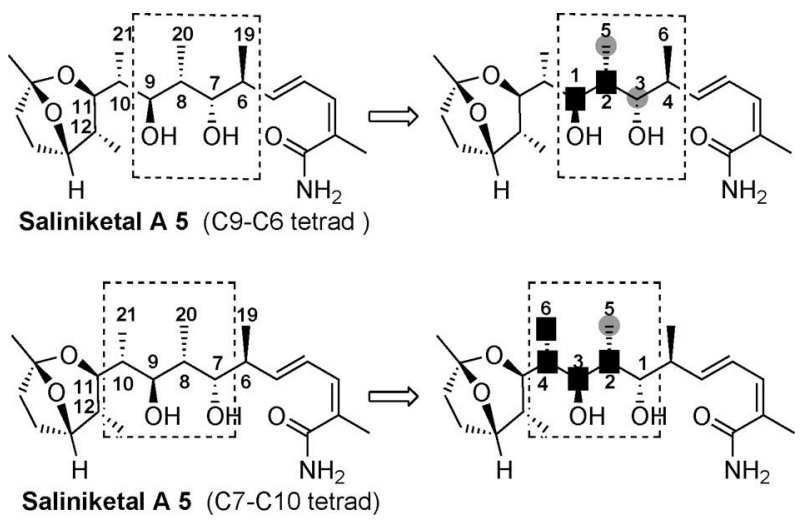

Scheme 8. Saliniketal A (5, C9-C6 and C7-C10 tetrads) examined by the statistical UDB approach.

The saliniketal A (5) pentad is a particular case, featuring a $\mathrm{C}-11$ substituted hydroxy group in a $\beta$ position to the $\mathrm{C} 9$ $\mathrm{C} 6$ tetrad and an $\alpha$ position to the $\mathrm{C} 7-\mathrm{C} 10$ unit. Because this is not a free hydroxy function, a third tetrad is not generated; however, the ether substituent induces new $\gamma$ and $\delta$ effects that must be taken into account.

The C9-C6 tetrad is substituted by an $\alpha$ methyl and a $\beta$ cyclic ether group. In this specific environment, results obtained in a strict application of Kishi's original UDB method suggested an incorrect syn-anti-anti preferential configuration instead of the real anti-syn-anti (Table 8).
Table 8. Statistical study of the C9-C6 tetrad of $5\left({ }^{13} \mathrm{C}\right.$ NMR analysis).

\begin{tabular}{|c|c|c|c|c|c|c|c|c|}
\hline$\Delta \delta$ & $\Delta \delta$ & $\Delta \delta$ & $\Delta \delta$ & $\Delta \delta$ & $\Delta \delta$ & $\Delta \delta$ & $\Delta \delta$ & \\
\hline $1 \mathrm{a}$ & $1 b$ & $1 c$ & 1d & 1e & If & $1 \mathrm{~g}$ & $1 \mathrm{~h}$ & No. \\
\hline$s-a-s$ & $S-S-S$ & $s-a-a$ & $s-s-a$ & $a-a-s$ & $a-s-s$ & $a-a-a$ & $a-s-a$ & \\
\hline 16.01 & 19.10 & 8.98 & 16.91 & 20.13 & 16.57 & 15.40 & 17.39 & $\Sigma|\Delta \delta|$ \\
\hline 7.37 & 7.70 & 4.11 & 7.99 & 10.40 & 5.11 & 8.58 & 5.25 & $-1-3$ \\
\hline 4.03 & 5.04 & 2.20 & 5.86 & 5.48 & 1.87 & 3.77 & 2.52 & $-1-2-3$ \\
\hline 7.21 & 4.77 & 3.78 & 3.86 & 9.36 & 4.91 & 7.07 & 4.64 & $-1-3-5$ \\
\hline
\end{tabular}

This observation constitutes an example in which additional $\gamma$ and $\delta$ effects lead to misinterpretation. By our statistical approach, three configurations appeared to be likely (syn-anti-anti, anti-syn-syn and anti-syn-anti) when stereocentres that support $\gamma$ and $\delta$ effects, induced by external substituents on the C9-C6 tetrad, were alternatively or simultaneously not taken into account (Table 8).

In parallel, analysis of the $\mathrm{C} 7-\mathrm{C} 10$ unit (substituted by $\alpha$ and $\beta^{\prime}$ methyl groups and an $\alpha^{\prime}$ cyclic ether) revealed a preferential syn-anti-anti configuration without any doubt (Table 9).

Table 9. Statistical study of the C7-C10 tetrad of $5\left({ }^{13} \mathrm{C}\right.$ NMR analysis).

\begin{tabular}{|c|c|c|c|c|c|c|c|c|}
\hline$\Delta \delta$ & $\Delta \delta$ & $\Delta \delta$ & $\Delta \delta$ & $\Delta \delta$ & $\Delta \delta$ & $\Delta \delta$ & $\Delta \delta$ & \\
\hline 1a & $1 b$ & $1 c$ & 1d & 1e & If & $1 \mathrm{~g}$ & $1 \mathrm{~h}$ & No. \\
\hline$s-a-s$ & $S-S-S$ & $s-a-a$ & $s-s-a$ & $a-a-s$ & $a-S-S$ & $a-a-a$ & $a-s-a$ & \\
\hline 13.61 & 13.94 & 7.38 & 14.55 & 17.73 & 14.17 & 13.80 & 14.99 & $\Sigma|\Delta \delta|$ \\
\hline 5.99 & 9.54 & 4.90 & 11.90 & 9.76 & 6.21 & 8.88 & 7.29 & $-3-2$ \\
\hline 3.15 & 8.60 & 3.84 & 11.88 & 6.40 & 6.09 & 7.23 & 7.17 & $-3-2-6$ \\
\hline 7.70 & 10.43 & 4.60 & 11.68 & 13.00 & 7.30 & 11.68 & 7.63 & $-3-4$ \\
\hline 7.54 & 7.50 & 4.27 & 7.55 & 11.96 & 7.10 & 10.17 & 7.02 & $-3-4-5$ \\
\hline
\end{tabular}

The unambiguous syn-anti-anti prediction for the $\mathrm{C} 7$ C10 tetrad implied an anti-syn-x structure for the C9-C6 unit, but there was still uncertainty between the two antisyn-syn and anti-syn-anti possibilities. As a consequence, statistical analysis of saliniketal A (5) by ${ }^{13} \mathrm{C}$ NMR spectroscopy predicted the C7-C10 tetrad configuration. However, the stereochemistry at the C6 centre remained uncertain.

Notably, thanks to statistical ${ }^{13} \mathrm{C}$ NMR analysis, full structural elucidation could have been achieved through the synthesis of only two isomers and their comparison with
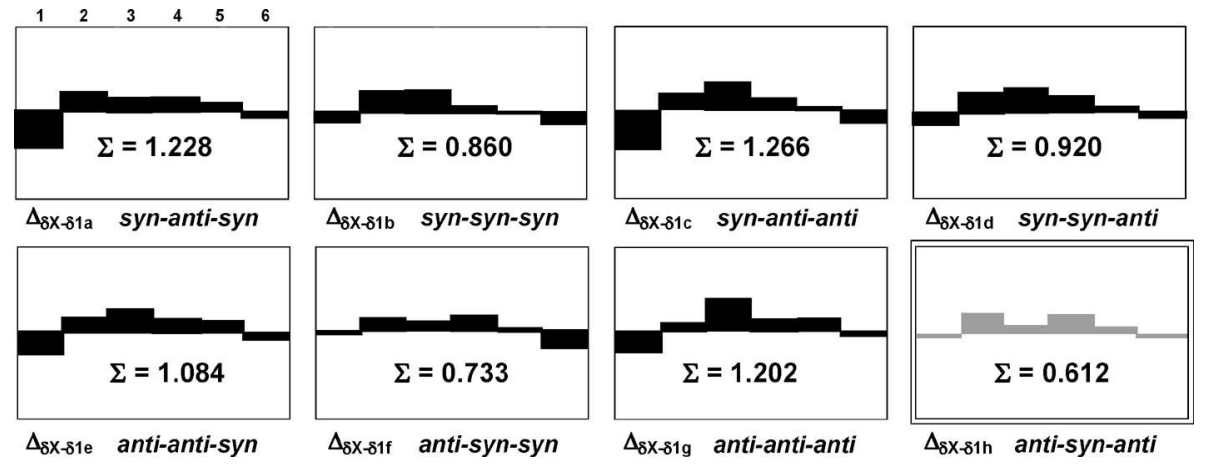

Figure 3. Histograms for the C9-C6 tetrad of $5\left({ }^{1} \mathrm{H}\right.$ NMR analysis). 
the natural product instead of the sixteen that would initially have been required.

Because no conclusion relating to the $\mathrm{C} 6$ position could be drawn from ${ }^{13} \mathrm{C} \mathrm{NMR},{ }^{1} \mathrm{H}$ NMR examination of the C9-C6 tetrad by the original UDB method was performed, in accordance with Kishi's proposal. ${ }^{[4]}$

The results obtained in the ${ }^{1} \mathrm{H}$ NMR analysis of the C9C6 unit showed that the anti-syn-anti configuration appeared to be favoured $(\Sigma=0.612$; see Figure 3$)$.

Consequently, the determination of the anti-syn-anti-anti relative stereochemistry of the C6-C10 unit of saliniketal 5 was achieved through a combination of statistical ${ }^{13} \mathrm{C}$ and classical ${ }^{1} \mathrm{H}$ NMR studies.

\section{Structural Assignment of Hexad Structures}

Encouraged by successful results relating to pentad units, we turned to the examination of hexad patterns.

\section{NMR Analysis of the C2-C7 Hexad of the Synthetic Aflastatin Fragment 4}

The synthetic aflastatin fragment $\mathbf{4}$, incorporating a C2C7 tripropionate unit, was selected for this first analysis (Schemes 4 and 9). For this situation, the ${ }^{13} \mathrm{C}$ NMR examination was partitioned into three tetrads (C3-C6, C7-C4 and $\mathrm{C} 5-\mathrm{C} 2$ ).
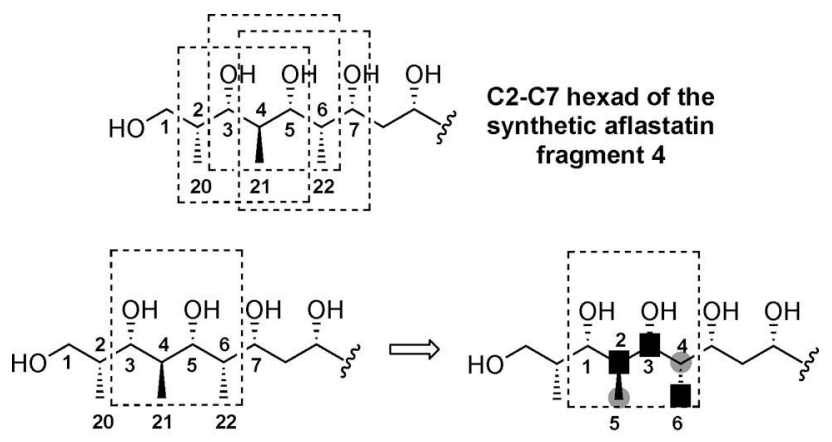

C3-C6 tetrad

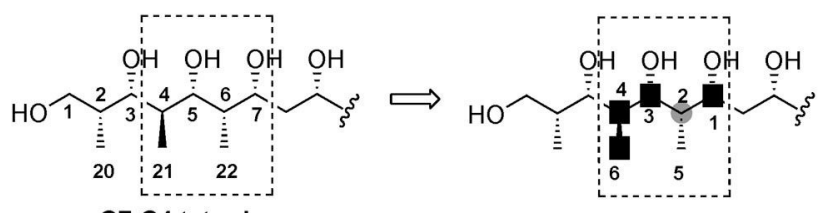

C7-C4 tetrad

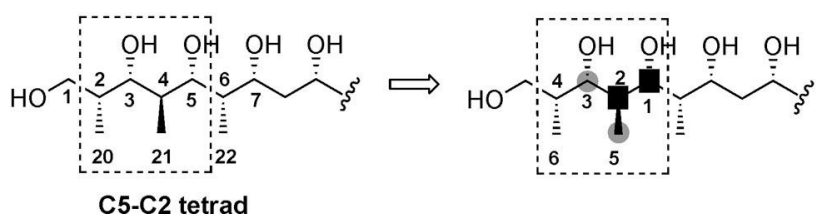

Scheme 9. C2-C7 hexad of the synthetic aflastatin fragment 4 examined by the statistical UDB approach.

For the C3-C6 tetrad, two configurations emerged as satisfactory candidates: syn-anti-syn and anti-anti-syn (Table 10).
Table 10. Statistical study of the C3-C6 tetrad of $4\left({ }^{13} \mathrm{C}\right.$ NMR analysis).

\begin{tabular}{rcccccccc}
\hline$\Delta \delta$ & $\Delta \delta$ & $\Delta \delta$ & \multicolumn{1}{c}{$\Delta \delta$} & \multicolumn{1}{c}{$\Delta \delta$} & \multicolumn{1}{c}{$\Delta \delta$} & \multicolumn{1}{c}{$\Delta \delta$} & \multicolumn{1}{c}{$\Delta \delta$} & \\
$\mathbf{1 a}$ & $\mathbf{1 b}$ & $\mathbf{1 c}$ & $\mathbf{1 d}$ & \multicolumn{1}{c}{$\mathbf{1 e}$} & \multicolumn{1}{c}{$\mathbf{1 f}$} & \multicolumn{1}{c}{$\mathbf{1 g}$} & \multicolumn{1}{c}{$\mathbf{1 h}$} & No. \\
$s-a-s$ & $s-s-s$ & $s-a-a$ & \multicolumn{1}{c}{$s-s-a$} & $\boldsymbol{a}-\boldsymbol{a - s}$ & \multicolumn{1}{c}{$a-s-s$} & \multicolumn{1}{c}{$a-a-a$} & \multicolumn{1}{c}{$a-s-a$} & \\
\hline $\mathbf{1 9 . 6 5}$ & 25.14 & 21.30 & 28.69 & $\mathbf{2 0 . 2 5}$ & 25.85 & 21.58 & 27.69 & $\Sigma|\Delta \delta|$ \\
$\mathbf{9 . 0 7}$ & 17.10 & 14.43 & 21.87 & $\mathbf{1 0 . 9 0}$ & 14.83 & 15.17 & 16.42 & -3 \\
$\mathbf{8 . 6 1}$ & 15.96 & 12.54 & 20.20 & $\mathbf{9 . 7 8}$ & 14.27 & 14.16 & 15.35 & $-2-3$ \\
$\mathbf{6 . 5 1}$ & 11.77 & 12.36 & 15.34 & $\mathbf{9 . 5 4}$ & 12.23 & 14.28 & 13.41 & $-3-5$ \\
$\mathbf{8 . 8 1}$ & 14.94 & 10.27 & 18.75 & $\mathbf{1 0 . 6 4}$ & 11.85 & 10.42 & 13.44 & $-3-6$ \\
$\mathbf{5 . 8 4}$ & 13.73 & 10.62 & 17.92 & $\mathbf{7 . 6 2}$ & 11.08 & 11.56 & 12.43 & $-3-4$ \\
$\mathbf{8 . 3 5}$ & 13.80 & $\mathbf{8 . 3 8}$ & 17.08 & $\mathbf{9 . 5 2}$ & 11.29 & 9.41 & 12.37 & $-3-2-6$ \\
$\mathbf{5 . 3 8}$ & 12.59 & 8.73 & 16.25 & $\mathbf{6 . 5 0}$ & 10.52 & 10.55 & 11.36 & $-3-2-4$ \\
$\mathbf{6 . 2 5}$ & 9.61 & $\mathbf{8 . 2 0}$ & 12.22 & $\mathbf{9 . 2 8}$ & $\mathbf{9 . 2 5}$ & 9.53 & 10.43 & $-3-5-6$ \\
$\mathbf{3 . 2 8}$ & 8.40 & 8.55 & 11.39 & $\mathbf{6 . 2 6}$ & 8.48 & 10.67 & 9.42 & $-3-4-5$ \\
\hline
\end{tabular}

On application of the statistical analysis, the second fragment (C7-C4) appeared to possess an unambiguous synsyn-anti relative stereochemistry (Table 11).

Table 11. Statistical study of the C7-C4 tetrad of $4\left({ }^{13} \mathrm{C}\right.$ NMR analysis).

\begin{tabular}{rcccccccl}
\hline$\Delta \delta$ & $\Delta \delta$ & $\Delta \delta$ & \multicolumn{1}{c}{$\Delta \delta$} & \multicolumn{1}{c}{$\Delta \delta$} & \multicolumn{1}{c}{$\Delta \delta$} & $\Delta \delta$ & \multicolumn{1}{c}{$\Delta \delta$} & \\
$\mathbf{1 a}$ & $\mathbf{1 b}$ & $\mathbf{1 c}$ & \multicolumn{1}{c}{$\mathbf{1 d}$} & $\mathbf{1 e}$ & \multicolumn{1}{c}{$\mathbf{1 f}$} & $\mathbf{1 g}$ & \multicolumn{1}{c}{$\mathbf{1 h}$} & No. \\
$s-a-s$ & \multicolumn{1}{c}{$s-s-s$} & \multicolumn{1}{c}{$s-a-a$} & \multicolumn{1}{c}{$\boldsymbol{s - s - \boldsymbol { a }}$} & \multicolumn{1}{c}{$a-a-s$} & \multicolumn{1}{c}{$a-s-s$} & $a-a-a$ & \multicolumn{1}{c}{$a-s-a$} & \\
\hline 33.97 & 23.68 & 26.06 & $\mathbf{1 8 . 8 5}$ & 33.77 & 29.69 & 26.48 & 28.83 & $\Sigma|\Delta \delta|$ \\
13.15 & 7.94 & 8.89 & $\mathbf{5 . 8 3}$ & 16.50 & 10.81 & 12.18 & 10.13 & $-1-3$ \\
12.22 & 6.87 & 7.38 & $\mathbf{4 . 1 8}$ & 15.52 & 9.36 & 10.87 & 8.44 & $-1-3-4$ \\
6.81 & 3.50 & 6.45 & $\mathbf{2 . 3 5}$ & 9.64 & 7.19 & 10.33 & 6.51 & $-1-3-6$ \\
10.38 & 5.71 & 6.97 & $\mathbf{3 . 5 5}$ & 12.10 & 7.62 & 7.56 & 7.21 & $-1-3-2-4$ \\
4.97 & 2.34 & 6.04 & $\mathbf{1 . 7 2}$ & 6.22 & 5.45 & 7.02 & 5.28 & $-1-3-2-6$ \\
11.31 & 6.78 & 8.48 & $\mathbf{5 . 2 0}$ & 13.08 & 9.07 & 8.87 & 8.90 & $-1-3-2$ \\
\hline
\end{tabular}

Examination of the last unit $(\mathrm{C} 5-\mathrm{C} 2)$ by statistical analysis allowed three favourable configurations - anti-anti-anti, anti-anti-syn and syn-anti-syn - to be proposed (Table 12).

Table 12. Statistical study of the C5-C2 tetrad of $4\left({ }^{13} \mathrm{C}\right.$ NMR analysis).

\begin{tabular}{ccccccccl}
\hline$\Delta \delta$ & $\Delta \delta$ & $\Delta \delta$ & $\Delta \delta$ & $\Delta \delta$ & $\Delta \delta$ & $\Delta \delta$ & $\Delta \delta$ & \\
$\mathbf{1 a}$ & $\mathbf{1 b}$ & $\mathbf{1 c}$ & $\mathbf{1 d}$ & $\mathbf{1 e}$ & $\mathbf{1 f}$ & $\mathbf{1 g}$ & $\mathbf{1 h}$ & No. \\
$s-a-s$ & \multicolumn{1}{c}{$s-s-s$} & $s-a-a$ & \multicolumn{1}{c}{$s-s-a$} & $\boldsymbol{a}-\boldsymbol{a}-\boldsymbol{s}$ & \multicolumn{1}{c}{$a-s-s$} & $a-a-a$ & \multicolumn{1}{c}{$a-s-a$} & \\
\hline 12.25 & 10.90 & 11.60 & 11.99 & $\mathbf{8 . 6 3}$ & 11.27 & $\mathbf{7 . 2 4}$ & 12.25 & $\Sigma|\Delta \delta|$ \\
$\mathbf{4 . 2 3}$ & 7.96 & 7.23 & 10.57 & $\mathbf{4 . 1 6}$ & 5.19 & $\mathbf{5 . 7 4}$ & 6.35 & $-1-3$ \\
$\mathbf{3 . 7 7}$ & 6.82 & 5.34 & 8.90 & $\mathbf{3 . 0 4}$ & 4.63 & $\mathbf{4 . 7 3}$ & 5.28 & $-1-3-2$ \\
$\mathbf{1 . 6 7}$ & $\mathbf{2 . 6 3}$ & 5.16 & 4.04 & $\mathbf{2 . 8 0}$ & $\mathbf{2 . 5 9}$ & $\mathbf{4 . 8 5}$ & 3.34 & $-1-3-5$ \\
\hline
\end{tabular}

Superposition of the predictions for each of the three studied tetrads led to an $x$-anti-anti-syn-syn prediction for the C2-C7 unit of synthetic aflastatin fragment 4.

Finally, ${ }^{1} \mathrm{H}$ NMR examination of the $\mathrm{C} 5-\mathrm{C} 2$ tetrad by Kishi's original UDB method implied a C5-C2 anti-antisyn structure (Figure 4).

By combination of these results, full structural elucidation of the C2-C7 unit of synthetic aflastatin fragment 4 could be achieved with good agreement with the true synanti-anti-syn-syn configuration. 


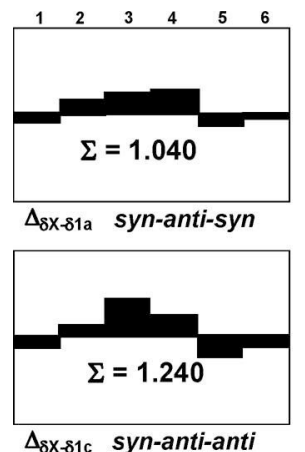

$\Delta_{8 \times-81 c}$ syn-anti-ant
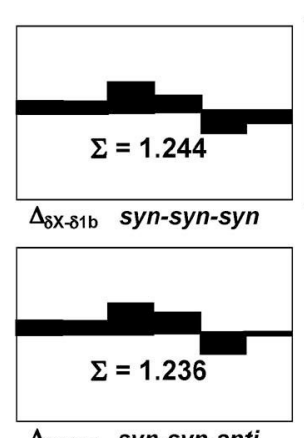

$\Delta_{8 \mathrm{x}-\delta 1 \mathrm{~d}}$ syn-syn-anti

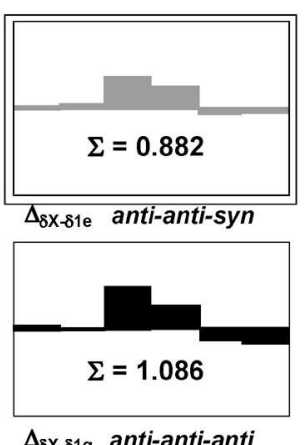

$\Delta_{\delta \mathrm{X}-\delta 1 \mathrm{~g}}$ anti-anti-anti
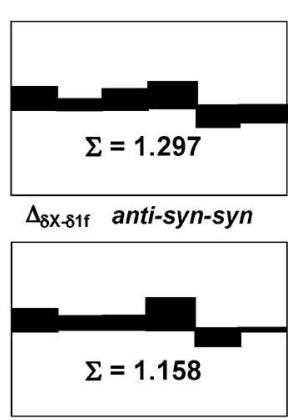

$\Delta_{\delta \mathrm{X}-\delta 1 \mathrm{~h}}$ anti-syn-anti

Figure 4. Histograms for the $\mathrm{C} 5-\mathrm{C} 2$ tetrad of $4\left({ }^{1} \mathrm{H}\right.$ NMR analysis).

\section{NMR Analysis of the C14-C19 Hexad of Sekothrixide (6)}

Sekothrixide (6) was the second hexad subjected to statistical UDB analysis (Schemes 4 and 10).

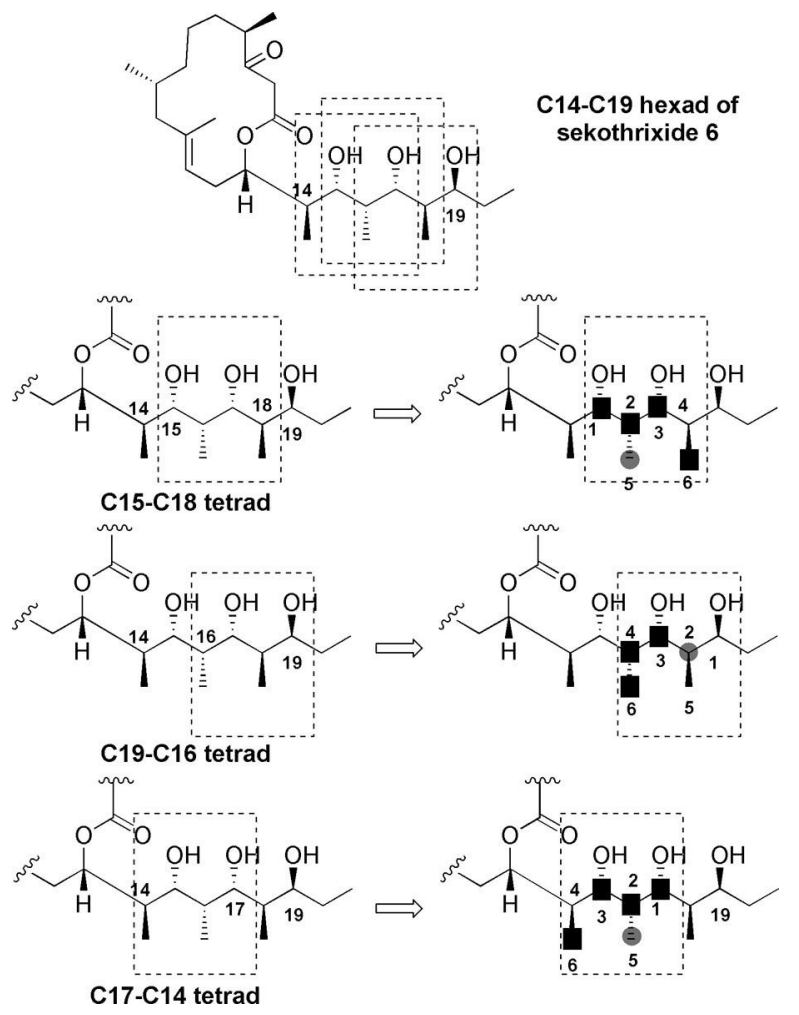

Scheme 10. C14-C19 hexad of sekothrixide (6) examined by the statistical UDB approach.

In the first $\mathrm{C} 15-\mathrm{C} 18$ tetrad (Table 13), two preferential relative configurations (syn-syn-syn and syn-syn-anti) were found to be the most plausible.

For the second C19-C16 segment, statistical analysis determined a syn-anti-syn configuration (Table 14).

The syn-anti-syn structure prediction for $\mathrm{C} 19-\mathrm{C} 16$ implied a syn-syn-anti relative stereochemistry for the C15C18 unit and renders a syn-syn-x configuration for the C17-C14 segment plausible.

Examination of the $\mathrm{C} 17-\mathrm{C} 14$ hexad by statistical ${ }^{13} \mathrm{C}$ NMR analysis (Table 15) did not identify a favourable candidate (although Kishi's original UDB method indicated a
Table 13. Statistical study of the tetrad C15-C18 of $6\left({ }^{13} \mathrm{C}\right.$ NMR analysis).

\begin{tabular}{rrrrrrrrl}
\hline$\Delta \delta$ & \multicolumn{1}{c}{$\Delta \delta$} & \multicolumn{1}{c}{$\Delta \delta$} & \multicolumn{1}{c}{$\Delta \delta$} & \multicolumn{1}{c}{$\Delta \delta$} & \multicolumn{1}{c}{$\Delta \delta$} & $\Delta \delta$ & \multicolumn{1}{c}{$\Delta \delta$} & \\
$\mathbf{1 a}$ & \multicolumn{1}{c}{$\mathbf{1 b}$} & \multicolumn{1}{c}{$\mathbf{1 c}$} & \multicolumn{1}{c}{$\mathbf{1 d}$} & \multicolumn{1}{c}{$\mathbf{1 e}$} & \multicolumn{1}{c}{$\mathbf{1 f}$} & \multicolumn{1}{c}{$\mathbf{1 g}$} & \multicolumn{1}{c}{$\mathbf{1 h}$} & No. \\
$s-a-s$ & \multicolumn{1}{c}{$s-s-s$} & $s-a-a$ & \multicolumn{1}{c}{$\boldsymbol{s - s - a}$} & \multicolumn{1}{c}{$a-a-s$} & \multicolumn{1}{c}{$a-s-s$} & \multicolumn{1}{c}{$a-a-a$} & \multicolumn{1}{c}{$a-s-a$} & \\
\hline 24.34 & $\mathbf{1 3 . 8 5}$ & 18.80 & $\mathbf{1 4 . 1 3}$ & 29.79 & 25.57 & 22.29 & 26.42 & $\Sigma|\Delta \delta|$ \\
16.72 & $\mathbf{6 . 6 8}$ & 12.74 & $\mathbf{6 . 4 2}$ & 20.71 & 12.67 & 16.08 & 12.99 & $-1-3$ \\
15.09 & $\mathbf{6 . 2 0}$ & 12.33 & $\mathbf{6 . 0 2}$ & 17.23 & 11.85 & 12.69 & 12.25 & $-1-3-2$ \\
8.45 & $\mathbf{5 . 5 9}$ & $\mathbf{4 . 7 1}$ & $\mathbf{5 . 8 5}$ & 11.34 & $\mathbf{5 . 4 5}$ & $\mathbf{6 . 3 2}$ & $\mathbf{6 . 1 1}$ & $-1-3-5$ \\
9.98 & $\mathbf{3 . 4 2}$ & 10.21 & $\mathbf{2 . 9 9}$ & 10.89 & 9.27 & 11.47 & 9.18 & $-1-3-2-6$ \\
3.34 & $\mathbf{2 . 8 1}$ & $\mathbf{2 . 5 9}$ & $\mathbf{2 . 8 2}$ & 5.00 & $\mathbf{2 . 8 7}$ & 5.10 & $\mathbf{3 . 0 4}$ & $-1-3-5-6$ \\
\hline
\end{tabular}

Table 14. Statistical study of the C19-C16 tetrad of $6\left({ }^{13} \mathrm{C}\right.$ NMR analysis).

\begin{tabular}{rcrccrrrl}
\hline$\Delta \delta$ & $\Delta \delta$ & $\Delta \delta$ & $\Delta \delta$ & $\Delta \delta$ & $\Delta \delta$ & $\Delta \delta$ & $\Delta \delta$ & \\
$\mathbf{1 a}$ & $\mathbf{1 b}$ & $\mathbf{1 c}$ & $\begin{array}{c}\mathbf{1 d} \\
s-s-\end{array}$ & $\mathbf{1 e}$ & $\mathbf{1 f}$ & $\mathbf{1 g}$ & $\mathbf{1 h}$ & No. \\
$s-a-s$ & $s-s-s$ & $s-a-a$ & \multicolumn{1}{c}{$a$} & $a-a-s$ & \multicolumn{1}{c}{$a-s-s$} & $a-a-a$ & $a-s-a$ & \\
\hline $\mathbf{1 6 . 7 2}$ & 25.85 & 20.18 & 26.83 & $\mathbf{1 6 . 2 1}$ & 25.03 & 18.95 & 25.74 & $\Sigma|\Delta \delta|$ \\
$\mathbf{9 . 1 5}$ & 22.18 & 15.34 & 23.04 & $\mathbf{1 0 . 3 1}$ & 15.11 & 15.78 & 15.41 & -3 \\
$\mathbf{5 . 0 4}$ & 17.45 & 10.76 & 18.22 & $\mathbf{6 . 3 9}$ & 10.66 & 11.67 & 10.71 & $-3-4$ \\
$\mathbf{4 . 2 7}$ & 15.53 & 8.77 & 16.22 & $\mathbf{5 . 3 1}$ & 9.08 & 10.68 & 9.05 & $-3-2-4$ \\
$\mathbf{8 . 3 8}$ & 20.26 & 13.35 & 21.04 & $\mathbf{9 . 2 3}$ & 13.53 & 14.79 & 13.75 & $-3-2$ \\
$\mathbf{5 . 8 6}$ & 16.56 & 9.06 & 17.67 & 8.25 & 9.29 & 8.60 & 10.08 & $-3-6$ \\
$\mathbf{5 . 0 9}$ & 14.64 & 7.07 & 15.67 & 7.17 & 7.71 & 7.61 & 8.42 & $-3-2-6$ \\
\hline
\end{tabular}

plausible syn-anti-anti configuration; see $\Sigma=13.54$ ). The relative stereochemistry at the $\mathrm{C} 14$ centre remained undetermined and only the structure of the $\mathrm{C} 15-\mathrm{C} 19$ fragment was predicted.

Table 15. Statistical study of the C17-C14 tetrad of $6\left({ }^{13} \mathrm{C}\right.$ NMR analysis).

\begin{tabular}{rrrrrrrrl}
\hline$\Delta \delta$ & $\Delta \delta$ & \multicolumn{1}{c}{$\Delta \delta$} & \multicolumn{1}{c}{$\Delta \delta$} & \multicolumn{1}{c}{$\Delta \delta$} & \multicolumn{1}{c}{$\Delta \delta$} & $\Delta \delta$ & \multicolumn{1}{c}{$\Delta \delta$} & \\
$\mathbf{1 a}$ & \multicolumn{1}{c}{$\mathbf{1 b}$} & \multicolumn{1}{c}{$\mathbf{1 c}$} & \multicolumn{1}{c}{$\mathbf{1 d}$} & \multicolumn{1}{c}{$\mathbf{1 e}$} & \multicolumn{1}{c}{$\mathbf{1 f}$} & \multicolumn{1}{c}{$\mathbf{1 g}$} & \multicolumn{1}{c}{$\mathbf{1 h}$} & No. \\
$s-a-s$ & $s-s-s$ & $s-a-a$ & \multicolumn{1}{c}{$s-s-\boldsymbol{a}$} & \multicolumn{1}{c}{$a-a-s$} & \multicolumn{1}{c}{$a-s-s$} & \multicolumn{1}{c}{$a-a-a$} & \multicolumn{1}{c}{$a-s-a$} & \\
\hline 18.06 & 19.55 & $\mathbf{1 3 . 5 4}$ & 20.11 & 20.19 & 21.27 & 19.11 & 20.80 & $\Sigma|\Delta \delta|$ \\
11.24 & 11.32 & $\mathbf{1 0 . 7 2}$ & 11.58 & 11.91 & $\mathbf{9 . 1 7}$ & 10.84 & $\mathbf{8 . 1 7}$ & $-1-3$ \\
6.87 & $\mathbf{5 . 8 0}$ & $\mathbf{5 . 1 3}$ & $\mathbf{5 . 9 8}$ & 9.39 & $\mathbf{3 . 9 9}$ & 8.23 & $\mathbf{2 . 9 1}$ & $-1-3-2$ \\
4.86 & 5.48 & $\mathbf{4 . 1 5}$ & 5.91 & 6.15 & $\mathbf{3 . 4 7}$ & 6.35 & $\mathbf{2 . 8 8}$ & $-1-3-2-6$ \\
$\mathbf{8 . 2 7}$ & $\mathbf{7 . 1 1}$ & $\mathbf{9 . 7 4}$ & 11.51 & $\mathbf{8 . 6 7}$ & $\mathbf{8 . 6 5}$ & $\mathbf{8 . 9 6}$ & $\mathbf{8 . 1 4}$ & $-1-3-5$ \\
6.26 & 6.79 & 7.01 & 6.78 & $\mathbf{4 . 6 0}$ & 6.73 & $\mathbf{4 . 5 0}$ & 6.56 & $-1-3-5-6$ \\
\hline
\end{tabular}

Once again, at this stage, the number of possible remaining isomers was strongly decreased thanks to statistical ${ }^{13} \mathrm{C}$ $N M R$ analysis (two instead of thirty-two). 


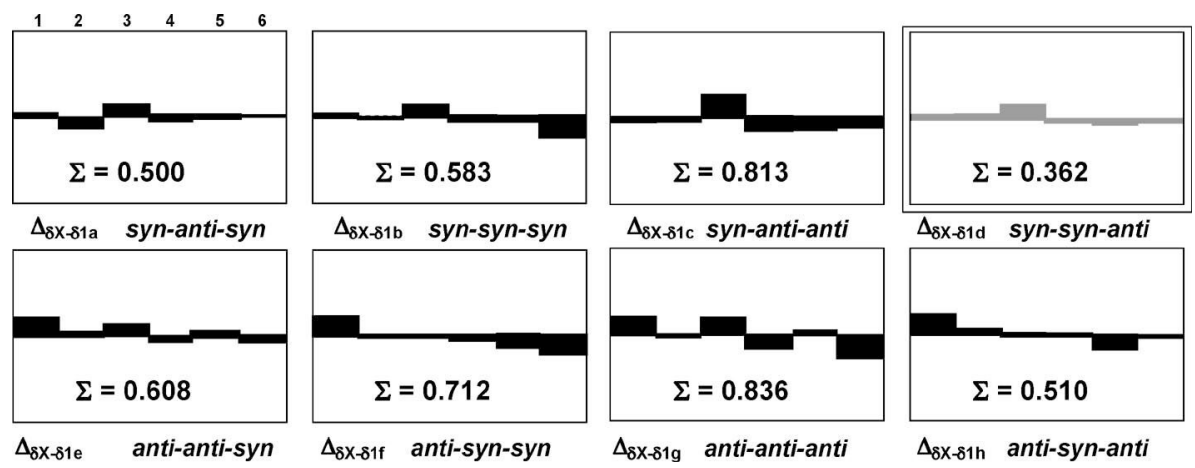

Figure 5. Histograms for the C17-C14 tetrad of $6\left({ }^{1} \mathrm{H}\right.$ NMR analysis).

As observed in the case of saliniketal $(\mathbf{5})$, classical ${ }^{1} \mathrm{H}$ NMR UDB analysis of the C17-C14 fragment gave evidence for the correct syn-syn-anti configuration (see Figure 5 and Supporting Information).

In this example, a combination of ${ }^{13} \mathrm{C}$ and ${ }^{1} \mathrm{H}$ NMR analysis was again required in order to determine the complete relative stereochemistry (anti-syn-syn-anti-syn) of the hexad of sekothrixide 6 .

\section{NMR Analysis of the C8-C13 Hexad of Zincophorin Methyl Ester (7)}

Finally, the C8-C13 hexad of zincophorin methyl ester (7) was examined (Schemes 4 and 11).
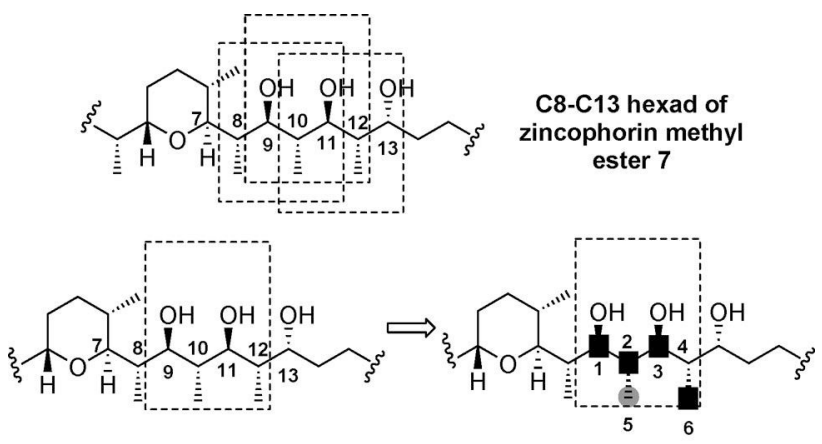

C9-C12 tetrad

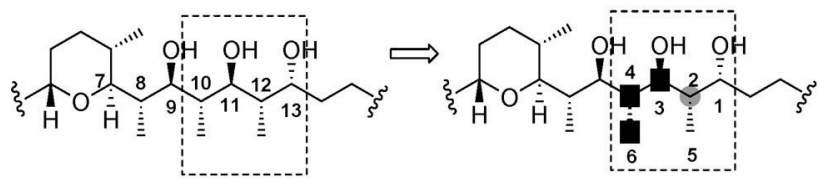

C13-C10 tetrad

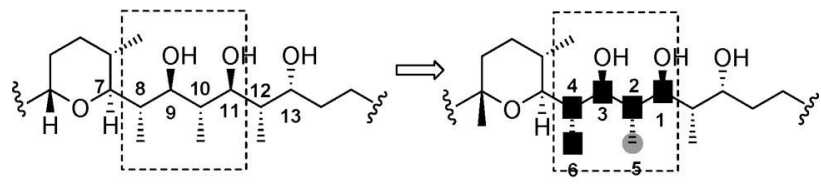

C11-C8 tetrad

Scheme 11. C8-C13 hexad of zincophorin methyl ester (7) examined by statistical UDB approach.

Strict statistical ${ }^{13} \mathrm{C}$ NMR analysis could only allow correct prediction of the C9-C13 segment (see Tables 16, 17 and 18).
Table 16. Statistical study of the C9-C12 tetrad of $7\left({ }^{13} \mathrm{C}\right.$ NMR analysis).

\begin{tabular}{|c|c|c|c|c|c|c|c|c|}
\hline $\begin{array}{c}\Delta \delta \\
\mathbf{1 a} \\
S-a-s\end{array}$ & $\begin{array}{c}\Delta \delta \\
\mathbf{1 b} \\
S-S-S\end{array}$ & $\begin{array}{c}\Delta \delta \\
\mathbf{1 c} \\
s-a-a\end{array}$ & $\begin{array}{c}\Delta \delta \\
\mathbf{1 d} \\
S-s-a\end{array}$ & $\begin{array}{c}\Delta \delta \\
\mathbf{1 e} \\
a-a-s\end{array}$ & $\begin{array}{c}\Delta \delta \\
\mathbf{1 f} \\
a-s-S\end{array}$ & $\begin{array}{c}\Delta \delta \\
\mathbf{1} \mathbf{g} \\
\boldsymbol{a}-\boldsymbol{a}-\boldsymbol{a}\end{array}$ & $\begin{array}{c}\Delta \delta \\
\mathbf{1 h} \\
a-s-a\end{array}$ & No. \\
\hline 26.04 & 25.31 & 23.52 & 25.95 & 24.43 & 25.13 & 17.21 & 26.58 & $\Sigma|\Delta \delta|$ \\
\hline 9.52 & 16.14 & 8.46 & 17.08 & 12.71 & 9.19 & 8.08 & 10.35 & $-1-3$ \\
\hline 9.35 & 14.82 & 7.07 & 15.68 & 14.39 & 8.21 & 6.49 & 9.29 & $-1-3-2$ \\
\hline 9.29 & 8.73 & 7.99 & 9.15 & 11.84 & 7.91 & 6.82 & 8.73 & $-1-3-5$ \\
\hline 5.44 & 13.24 & 6.15 & 13.85 & 9.25 & 6.83 & 6.47 & 7.42 & $-1-3-2-6$ \\
\hline 5.38 & 7.15 & 7.07 & 7.32 & 6.70 & 6.53 & 6.80 & 6.86 & $-1-3-5-6$ \\
\hline
\end{tabular}

Table 17. Statistical study of the C13-C10 tetrad of $7\left({ }^{13} \mathrm{C}\right.$ NMR analysis).

\begin{tabular}{|c|c|c|c|c|c|c|c|c|}
\hline$\Delta \delta$ & $\Delta \delta$ & $\Delta \delta$ & $\Delta \delta$ & $\Delta \delta$ & $\Delta \delta$ & $\Delta \delta$ & $\Delta \delta$ & \\
\hline $1 \mathrm{a}$ & $1 b$ & $1 c$ & 1d & $1 e$ & 1f & $1 \mathrm{~g}$ & 1h & No. \\
\hline$s-a-s$ & $S-S-S$ & $s-a-a$ & $s-s-a$ & $a-a-s$ & $a-s-s$ & $a-a-a$ & $a-s-a$ & \\
\hline 27.14 & 28.87 & 19.16 & 30.19 & 32.59 & 28.37 & 25.09 & 29.86 & $\Sigma|\Delta \delta|$ \\
\hline 15.67 & 21.30 & 10.42 & 22.50 & 22.79 & 14.55 & 18.02 & 15.63 & -3 \\
\hline 13.36 & 18.37 & 7.64 & 19.48 & 10.87 & 11.90 & 15.71 & 12.73 & $-3-4$ \\
\hline 10.46 & 15.19 & 8.20 & 19.37 & 16.35 & 11.87 & 16.70 & 12.46 & $-3-6$ \\
\hline 10.63 & 16.79 & 6.13 & 17.98 & 16.09 & 9.98 & 11.22 & 10.89 & $-2-3-4$ \\
\hline 7.73 & 16.84 & 6.69 & 17.87 & 11.77 & 9.95 & 12.21 & 10.62 & $-2-3-6$ \\
\hline
\end{tabular}

Table 18. Statistical study of the C11-C8 tetrad of $7\left({ }^{13} \mathrm{C}\right.$ NMR analysis).

\begin{tabular}{|c|c|c|c|c|c|c|c|c|}
\hline$\Delta \delta$ & $\Delta \delta$ & $\Delta \delta$ & $\Delta \delta$ & $\Delta \delta$ & $\Delta \delta$ & $\Delta \delta$ & $\Delta \delta$ & \\
\hline 1a & 1b & 1c & 1d & 1e & 1f & $1 \mathrm{~g}$ & 1h & No. \\
\hline$s-a-s$ & $S-S-S$ & $s-a-a$ & $s-s-a$ & $a-a-s$ & $a-s-s$ & $a-a-a$ & $a-s-a$ & \\
\hline 18.06 & 19.55 & 13.54 & 20.11 & 20.19 & 21.27 & 19.11 & 20.80 & $\Sigma|\Delta \delta|$ \\
\hline 11.24 & 11.32 & 10.72 & 11.58 & 11.91 & 9.17 & 10.84 & 8.17 & $-1-3$ \\
\hline 9.35 & 10.05 & 9.30 & 10.40 & 9.83 & 7.62 & 8.95 & 6.87 & $-1-3-4$ \\
\hline 6.87 & 5.80 & 5.13 & 5.98 & 9.39 & 3.99 & 8.23 & 2.91 & $-1-3-2$ \\
\hline 6.38 & 5.84 & 6.57 & 5.67 & 5.76 & 5.70 & 4.49 & 5.29 & $-1-3-4-5$ \\
\hline 4.86 & 5.48 & 4.15 & 5.91 & 6.15 & 3.47 & 6.35 & 2.88 & $-1-2-3-6$ \\
\hline 4.98 & 4.53 & 3.71 & 4.80 & 7.31 & 2.44 & 6.34 & 1.61 & $-1-2-3-4$ \\
\hline
\end{tabular}

${ }^{1} \mathrm{H}$ NMR analysis was again able to address this problem and the complete anti-anti-anti-anti-syn relationship was correctly predicted, once more corroborating the relevance of the method (see Figure 6 and Supporting Information). 


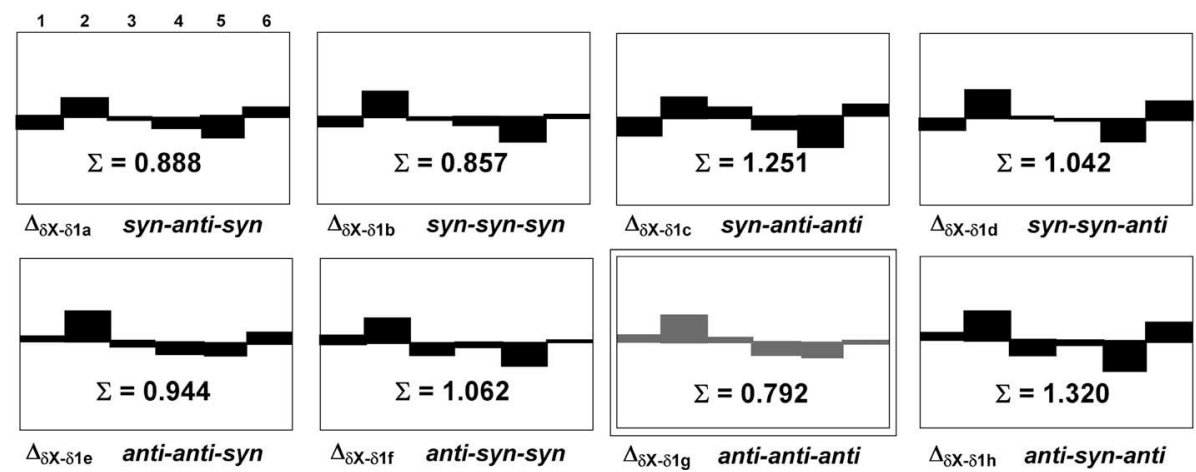

Figure 6. Histograms for the $\mathrm{C} 11-\mathrm{C} 8$ tetrad of $7\left({ }^{1} \mathrm{H}\right.$ NMR analysis).

\section{Conclusions}

Large polypropionates have relevant implications for several distinct research areas, such as natural products, structural elucidation, asymmetric synthesis, medicinal chemistry... Because of the challenge typically posed by the assignment of their configurations, here we suggest a general method for such determination based on conventional NMR spectroscopic examination of intact molecules. No derivatisation is needed and the procedure does not require the tedious synthesis of a new library of model stereoisomers.

The proposed method consists of an extension of Kishi's original ${ }^{13} \mathrm{C}$ NMR UDB approach through a statistical process. In most cases it was successfully applied to the stereochemical assignment of different pentads and hexads considered as a superpositions of tetrad units.

Notably, when a side-chain bears an $\alpha$-substitution that does not create a new tetrad, ${ }^{13} \mathrm{C}$ NMR prediction remains exact but partial, because a single asymmetric centre might not be determined. As previously envisioned by Kishi, classical ${ }^{1} \mathrm{H}$ NMR UDB analysis of the involved tetrad unit solves this problem and provides the full relative stereochemistry. However, this ${ }^{1} \mathrm{H}$ NMR support cannot be generalized at this time.

Supporting Information (see also the footnote on the first page of this article): Full data analysis of ${ }^{13} \mathrm{C}$ - and ${ }^{1} \mathrm{H}$ NMR values for all examples.

\section{Acknowledgments}

We thank Pierre Fabre Laboratories and the Centre National de la Recherche Scientifique (CNRS) for a doctoral fellowship for E. F.

[1] For prevision of the relative configuration see recent reviews: a) G. Bifulco, P. Dambruoso, L. Gomez-Paloma, R. Riccio,
Chem. Rev. 2007, 107, 3744-3779; b) D. Menche, Nat. Prod. Rep. 2008, 25, 905-918. Kishi's UDB method: c) W. Zheng, J. A. DeMattei, J.-P. Wu, J. J.-W. Duan, L. R. Cook, H. Oinuma, Y. Kishi, J. Am. Chem. Soc. 1996, 118, 7946-7968; d) Y. Kobayashi, J. Lee, K. Tezuka, Y. Kishi, Org. Lett. 1999, 1, 2177-2180; e) J. Lee, Y. Kobayashi, K. Tezuka, Y. Kishi, Org. Lett. 1999, 1, 2181-2184; f) Y. Kobayashi, C.-H. Tan, Y. Kishi, Helv. Chim. Acta 2000, 83, 2562-2571; g) Y. Kobayashi, C.-H. Tan, Y. Kishi, J. Am. Chem. Soc. 2001, 123, 2076-2078; h) A. B. Benowitz, S. Fidanze, P. L. C. Small, Y. Kishi, J. Am. Chem. Soc. 2001, 123, 5128-5129; i) S. Fidanze, F. Song, M. Szlosek-Pinaud, P. L. C. Small, Y. Kishi, J. Am. Chem. Soc. 2001, 123, 10117-10118. For prediction of absolute configuration: j) Y. Kobayashi, N. Hayashi, C.-H. Tan, Y. Kishi, Org. Lett. 2001, 3, 2245-2248; k) N. Hayashi, Y. Kobayashi, Y. Kishi, Org. Lett. 2001, 3, 2249-2252; 1) Y. Kobayashi, N. Hayashi, Y. Kishi, Org. Lett. 2001, 3, 2253-2255; m) Y. Kobayashi, N. Hayashi, Y. Kishi, Org. Lett. 2002, 4, 411-414.

[2] For examples, see: a) J. B. MacMillan, T. F. Molinski, Org. Lett. 2002, 4, 1535-1538; b) T. R. Hoye, M. A. Tennakoon, Org. Lett. 2000, 2, 1481-1483.

[3] Such a possibility was first envisioned by Kishi for the structural assignment of the desertomycin C29-C33 propionate fragment: C.-H. Tan, Y. Kobayashi, Y. Kishi, Angew. Chem. Int. Ed. 2000, 39, 4279-4281.

[4] For tetrads, Kishi's conventional way of reading was applied, starting from the hydroxy group.

[5] E. Breitmaier, W. Voelter, in: Carbon-13 NMR Spectroscopy: High-Resolution Methods and Applications in Organic Chemistry and Biochemistry, 3rd ed., Wiley-VCH, Weinheim, 1987.

[6] S. R. Chemler, W. R. Roush, J. Org. Chem. 2003, 68, 1319 1333.

[7] H. Ikeda, N. Matsumori, M. Ono, A. Suzuki, A. Isogai, H. Nagasawa, S. Sakuda, J. Org. Chem. 2000, 65, 438-444.

[8] P. G. Williams, R. N. Asolkar, T. Kondratyuk, J. M. Pezzuto, P. R. Jensen, W. Fenical, J. Nat. Prod. 2007, 70, 83-88.

[9] Y. J. Kim, K. Furihata, A. Shimazu, K. Furihata, H. Seto, J. Antibiot. 1991, 44, 1280-1282.

[10] M. Defosseux, N. Blanchard, C. Meyer, J. Cossy, J. Org. Chem. 2004, 69, 4626-4647. 